\title{
Contribuições da mística de Santa Teresa de Jesus para o diálogo inter-religioso
}

Lúcia Pedrosa-Pádua

\section{Resumo}

Santa Teresa de Jesus viveu em um contexto histórico intolerante para com outras religiões e nunca tratou explicitamente sobre o diálogo inter-religioso. Ela pode, porém, contribuir para a reflexão atual sobre este tema através de sua vida e doutrina. Neste artigo são desenvolvidos quatro níveis desta contribuição. $\mathrm{O}$ primeiro diz respeito às disposições necessárias para um verdadeiro diálogo: a humildade, a primazia do amor concreto e a determinação para a comunicação. O segundo nível é o reconhecimento de que outras religiões, no caso o judaísmo e o islamismo, exerceram influências, em escalas diversas, na experiência e nos escritos místicos teresianos. Influências análogas acontecem em nosso contexto atual, multicultural e plurirreligioso, e devem ser valorizadas. No terceiro nível, são destacados três elementos concretos da doutrina mística de Teresa de Jesus com potencial de diálogo entre as religiões: a oração de recolhimento, a relação intrínseca entre mística e ética e a dupla experiência da presença de Deus em tudo e de tudo em Deus. Finalmente, é destacado o nível antropológico: a mística de Santa Teresa de Jesus vai ao essencial da aventura humana nesta vida.

Palavras-chave: Santa Teresa de Jesus, Mística, Diálogo Inter-Religioso 


\begin{abstract}
Saint Teresa of Jesus lived in a time of intolerance towards other religions and never explicitly approached the dialog between religions. She can however, contribute today to the study of this subject through her life and her doctrine. In this article, four levels of such contribution are developed. The first one is related to the necessary dispositions for true dialog: humility, the primacy of concrete love and the determination to communicate. The second level is the acknowledgment that other religions, in this case Judaism and Islam, influenced, on different levels, the mystical experience and the writings of St. Teresa. Similar influences occur in our multicultural and multi-religions context and should be valued. On a third level, three concrete elements of the mystical doctrine of St. Teresa with potential to create dialog between religions are_highlighted: the private prayer, the inner link between mysticism and ethics and the double experience of the God in everything and in everything of God. Finally, the anthropological level is approached: the mysticism of Saint Teresa reaches what is essential in the human adventure in this life.
\end{abstract}

Keywords: Saint Teresa of Jesus, Mysticism, Inter-Religious Dialogue.

\title{
Introdução
}

Este estudo apresenta uma contribuição concreta da mística cristã para o diálogo inter-religioso. Trata-se de Santa Teresa de Jesus, a mística de Ávila do século XVI, reformadora, fundadora e escritora que, junto com Santa Catarina de Sena, foi a primeira mulher declarada Doutora da Igreja. ${ }^{1}$

Dois esclarecimentos iniciais são necessários. Primeiramente que, aqui, a compreensão de mística se faz no interior da complexidade semântica explicitada pelo Pe. Vaz. ${ }^{2}$ Assim, o vocábulo místico diz respeito tanto à experiência relativa ao Mistério, quanto à pessoa do místico que realiza a experiência e aos seus escritos, realizados geralmente em momento posterior

\footnotetext{
${ }^{1}$ Para uma introdução e atualização da figura de Santa Teresa, indico o livro recém-publicado: Lúcia PEDROSA-PÁDUA e Mônica B. CAMPOS (orgs.), Santa Teresa: mística para o nosso tempo. São Paulo/ Rio de Janeiro, Reflexão/ PUC-Rio, 2011.

${ }^{2}$ Henrique C. L. VAZ, Experiência mística e filosofia na tradição ocidental. Loyola, São Paulo, 2000, p. 18.
} 
e anamnético à intensa experiência mística. Por isso, dizemos experiência mística, chamamos seus sujeitos de místicos e aos seus escritos de literatura mística ou simplesmente a mística.

O segundo necessário esclarecimento é o de que Teresa, em sua maturidade, não viveu em tempos de tolerância nem desfrutou de um ambiente disposto ao diálogo inter-religioso, embora a Espanha tenha testemunhado uma singular coexistência entre cristãos, muçulmanos e judeus durante oito séculos. ${ }^{3}$ Lembremos que a cidade de Córdoba chegou a ser sede do califado. Porém, ao final do século XV, com os reis católicos, é completada a expulsão dos judeus e o último reduto muçulmano, Granada, é conquistado. Além disso, no século XVI, Espanha se protegerá tenazmente de qualquer movimento advindo da Reforma. Portanto, o contexto de Santa Teresa é o de empenho por unidade geográfica, política e religiosa, portanto cristã e católica.

Apesar e para além da homogeneização religiosa, a experiência mística comporta traços universais, porque vai ao núcleo de uma religião, a experiência do Mistério. Assim sendo, torna-se luminosa para o diálogo entre as religiões. Apresentaremos quatro níveis do que julgamos ser uma contribuição teresiana para esse diálogo.

\section{Nível. Desenvolver disposições necessárias ao diálogo}

Teresa é uma mulher que entra numa verdadeira zona de fogo, que é a experiência mística. São experiências intensas, purificadoras, diversificadas e simplificadoras. A partir desta atalaia, surgem na mística teresiana algumas convicções que nos parecem basilares para um diálogo. Dentre elas destacamos a humildade, o amor e a comunicação. ${ }^{4}$

\section{a) A humildade}

No livro das Moradas, Teresa apresenta sua famosa expressão: "a humildade é andar em verdade". O melhor é ouvir a própria autora:

\footnotetext{
${ }^{3}$ Cf. M. Guadalupe PEDRERO-SÁNCHEZ, A Península Ibérica entre o oriente e o ocidente. Cristãos, muçulmanos e judeus. Atual, São Paulo, 2002.

${ }^{4}$ Cf. o sugestivo estudo de Gerson L. PEREIRA, "Luzes da espiritualidade teresiana para o diálogo ecumênico e inter-religioso atual", no já referido livro PEDROSA-PÁDUA e CAMPOS (orgs.). Santa Teresa..., pp. 203-225.
} 
“estando uma vez considerando porque razão Nosso Senhor era tão amigo da virtude da humildade, deparei logo (a meu ver, sem que eu o considerasse, de modo repentino) com o seguinte: é porque Deus é a suma Verdade e a humildade é andar em verdade" (6Moradas 10,7$).{ }^{5}$

E a verdade, continua ela, é que nós não devemos ter a nós mesmos em tão alta conta, mas perceber nossa "miseria e ser nada". Quem se tem em alta conta não entende isto, anda na mentira. E "quem mais o entender agradará mais à suma Verdade, porque andará nela". E termina com uma oração: "que Deus nos ajude, irmãs, a não sair jamais deste conhecimento próprio, amém" (6Moradas 10,7$)$.

Trata-se, portanto, da humildade profunda de quem se coloca em relação de dependência de Deus, abandonando a atitude orgulhosa de considerar-se autossuficiente. Teresa possui profunda consciência da miséria humana e da misericórdia de Deus que ama, perdoa, liberta e salva. Portanto, conhecer-se profundamente é colocar-se em relação a Deus, como fez o modelo de humildade, Jesus, sempre em relação com o Pai. A experiência de humildade é fundada no próprio testemunho de Deus, em Cristo.

Teresa sabe que a capacidade do amor de Deus não pode ser medida. É interessante verificar como ela caracteriza o "letrado", ou bom teólogo, como aquele que sabe "do que Deus é capaz", e isto não porque este conheça a medida do amor divino, mas precisamente por não colocar medidas a esse amor. $\mathrm{O}$ bom teólogo, diz ela, "nunca se espanta da grandeza de Deus" (5Moradas 1,7). Esta atitude humilde diferenciará o "letrado" daqueles que ela chama de "semiletrados", que ao final acabam duvidando do amor de Deus com seus medos.

Saber-se dependente de Deus traz consigo igualmente não orgulhar-se de si diante dos irmãos e não colocar-se em situação de superioridade. Testemunho maior é o do próprio Jesus, que se fez escravo de todos. ${ }^{6}$ A humildade é a dama que dá xeque-mate ao rei, compara Teresa, utilizando uma imagem do jogo de xadrez. ${ }^{7}$ Ela é o fundamento de uma vida espiritual e religiosa firme, é a companheira do amor e do desapego.

\footnotetext{
${ }^{5}$ Nas citações será utilizada, em geral, TERESA DE JESUS, Obras Completas. [Frei Patricio Sciadini (coord.), texto estabelecido pelo Frei Tomás ALVAREZ], Carmelitana/Loyola, São Paulo, 1995. Indicações para as obras teresianas: Livro da Vida: Vida; Caminho de Perfeição: Caminho; Castelo Interior ou Moradas: Moradas (o algarismo antes da abreviatura indica a morada correspondente).

${ }^{6}$ Cf. 7 Moradas 4,8 .

${ }^{7}$ Cf. Caminho de Perfeição 16,2.
} 
A humildade, virtude que nos faz ver, ao mesmo, dependentes de Deus e confiantes nele, impede todo exclusivismo porque o místico "sabe do que Deus é capaz". Ele não duvida da misericórdia, ao contrário, canta a misericórdia de Deus para com todos, sem exceções. Canta a condescendência de Deus que se abaixa para se comunicar, estar com e manter suas criaturas. E impede todo relativismo, pois caminhos de arrogância não levam à verdade - eles são a mentira, pois nada é ou se sustenta fora da relação com Deus.

\section{b) A primazia do amor concreto e da solidariedade}

A experiência mística não é um fim em si mesma, mas um caminho para o amor e a transformação espiritual e ética. Teresa esclarece, antes de entrar na narrativa de suas mais intensas experiências de união com Deus, que a verdadeira união com Deus é o amor ao próximo. ${ }^{8}$ Portanto, a mística conduz à disposição para amar concretamente. Trata-se de um amor que se traduz em trabalho. Até o matrimônio espiritual é descrito como realidade que exige obras. ${ }^{9}$ A oração é para que possamos trabalhar, agir, amar concretamente: "para isto é oração... para isto serve este matrimônio espiritual: para fazer nascer sempre obras, obras." (7Moradas 4, 6).

E o amor concreto, por acontecer num mundo de violência e sofrimento, é redentor. Porque é solidário na dor e no sofrimento humanos, frutos do afastamento desta realidade primordial do amor. Esta dor é primeiramente de Deus, bem sabem os místicos. Dor de Getsâmane, dor de Cristo ao sentir o fechamento ao amor, dor esta que para Teresa é maior que a paixão.

Neste sentido, trazemos aqui, a modo de ilustração, uma das narrativas místicas mais intensas de Teresa. Nela, a Santa demonstra como se sente interiormente torturada pelo afastamento de Deus dos que ela chama "hereges e mouros" que se perdem, descrita em 5Moradas 2,10-11. Observemos que ela cita aqueles grupos que, segundo as informações que chegam a ela, sempre parciais, estão inseridos em contextos de violência com relação aos cristãos católicos, no caso os huguenotes e os muçulmanos. Porém, o que mais a tortura, segundo a mesma narrativa, é o sofrimento e perda de muitos cristãos que, apesar de conhecerem o caminho, não o seguem. Ao final da narrativa, unindo cristãos, muçulmanos e reformados, ela afirma numa prece: "estes que se condenam são filhos de Deus e irmãos meus". Nesta narrativa, há um aprofundamento no conhecimento do sofrimento e da solidariedade de Deus por

\footnotetext{
${ }^{8}$ Cf. 5Moradas 3,6-12.

${ }^{9}$ Cf. 7 Moradas 2,1 .
} 
todos, bem como da universalidade do sofrimento humano. Esta realidade provoca profunda solidariedade por parte do místico.

É curioso que ela não se refira aos judeus. Seria porque ela, Teresa, sabia ser neta de "cristãos novos"?

Mesmo em contexto tão exclusivista como o século XVI, Teresa reivindica fraternidade radical da humanidade. Afirma a exigência do amor concreto e pondera como este amor é exigência de luta contra o mal, por motivos teológicos e antropológicos. Todo mal, e aqui aparecem de forma especial as divisões e violências por motivos religiosos, é sofrimento de Deus e da humanidade. Somos todos irmãos e somos todos pecadores, carentes de solidariedade, nesta única família humana.

\section{c) Comunicação e diálogo}

Uma terceira chave para o diálogo, na mística teresiana, é a necessária atitude de comunicação em tudo, fundamental para a espiritualidade. Se há uma categoria privilegiada para a relação entre Deus e a humanidade é a de comunhão e comunicação. "Quanto mais santas mais conversáveis", é expressão sua em Caminho de Perfeição $(41,7)$, na contramão da noção silenciosa de santidade. Oração é conversa, santidade é conversa. Deus é comunicação. Portanto, ser relacional e dialogal constitui instrinsecamente nossa peregrinação em humildade neste mundo. Teresa não teme conflitos e não poupa elogios. Uma olhada em seu vasto epistolário já nos traria preciosos dados sobre sua capacidade comunicativa, sua disposição em estabelecer pontes, a formação de redes de solidariedade e sua fina capacidade de formar comunidades verdadeiras. ${ }^{10}$

A não comunicação é uma perda: de amizade, de parentesco. "Parentesco e amizade se perdem com a falta de comunicação" (Caminho 26,9). E somos todos irmãos, percebera ela. Não percamos, pois, nossos irmãos de religiões diferentes pela falta de diálogo.

Resumindo, a humildade, o amor e a comunicação são valores-base teresianos, fundados na experiência de um Deus humilde e amoroso, que quer se comunicar. Desta forma, seriam chaves hermenêuticas do diálogo inter-religioso, que deve basear-se na humildade e amor de Deus sem medidas. Humildade, amor e comunicação são disposições que traduzem o que pode haver de mais profundo da experiência mística teresiana.

${ }^{10}$ Trabalhei este tema no capítulo Relações e afeto nas cartas de Santa Teresa. In: PEDROSAPÁDUA e CAMPOS (orgs.). Santa Teresa..., pp. 187-201. 


\section{Nível. Reconhecer a influência de outras religiões na experiência e escritos místicos de Santa Teresa}

A existência de Teresa é configurada num encontro velado de religiões. Encontro velado porque o século XVI, também chamado "século de ouro" espanhol, impôs a pureza do sangue católico e perseguiu judeus e muçulmanos.

Mas Teresa recebe a influência de ambos, judeus e muçulmanos. ${ }^{11}$

$\mathrm{O}$ avô de Teresa pertencia ao grupo de cristãos novos, obrigados a se converter do judaísmo ao cristianismo, e Teresa de Jesus sabia disso. Em sua infância, dos 4 aos 8 anos de idade, ela viveu, dentro de casa, as idas e vindas do processo de compra do título de fidalguia de sua família, para que eles se tornassem nobres acima de suspeitas e, portanto do preconceito e sansões sociais.

Isto teve consequências para a vida de Teresa. Primeiro, possibilitou a ela pertencer a uma família leitora. O pai possuía uma biblioteca com bons livros e gostava que os filhos lessem. Alguns estudos mostram que a menina leitora, aos sete anos, só era possível, naquele século, em famílias com consciência da importância do livro e se perguntam se a tradição judaica não teria tido importância nesta orientação.

Em seus escritos místicos, Teresa debate firmemente contra o regime de honras e parentescos da sua sociedade. Ela tinha experiência própria dos efeitos destrutivos da defesa da honra a qualquer custo. Em sua sociedade, os judeus não tinham honra. Tudo isto fará de Teresa uma verdadeira militante contra o regime de honras e privilégios dentro de seus conventos.

Teresa realizará um movimento contrário ao do fechamento e autodefesa, e prodigalizará amizades para com todos em sua vida. Será livre diante do diferente. Exemplo disso será a abertura e amizade para com um nobre português, D. Teutônio de Bragança, que chegou a ser arcebispo de Évora, sabidamente intolerante para com judaizantes e neo-cristãos. Certamente D. Teutônio saiu enriquecido desta relação, quem sabe menos cioso de suas honras e mais humilde.

Finalmente, voltando ao fato de que Teresa não cita os judeus quando menciona "hereges e mouros", como "estes que se perdem" (já narrado acima),

\footnotetext{
${ }^{11}$ A literatura é vasta. Cito apenas Tomás ALVAREZ. Santa Teresa de Jesús. Madre de los espirituales. Monte Carmelo, Burgos, 2004, pp. 16-21 e Luce LÓPEZ BARALT, Santa Teresa de Jesús y el Islam. Los símbolos de los siete castillos concêntricos. Teresianum 33 (1982) 629-678.
} 
podemos nos perguntar: proximidade, parentesco e amizade com pessoas de outras religiões pode suportar tamanho julgamento?

Da influência muçulmana sabemos através de estudos mais recentes dos islamistas sobre o século XVI, especialmente Asin Palacios e sua seguidora, Luce Lopez Baralt. Sobressai nestes estudos a possível influência muçulmana sobre o símbolo maior da mística teresiana, o castelo interior. A pesquisa dos islamistas demonstra que, na literatura islâmica, de ampla influência na Espanha medieval, constam um texto que compara o interior de todo filho de Adão a "sete castelos" e outro que descreve o esquema simbólico de sete castelos concêntricos no coração dos que crêem. Esta literatura pode ter inspirado o símbolo de castelo interior de Santa Teresa, evidentemente não como única fonte de inspiração, tampouco uma influência consciente e direta, mas sim, como influência difusa na cultura, que afeta a percepção e a linguagem.

Portanto, a experiência teresiana não pode ser vista fora deste contexto cultural, religioso e familiar em que Teresa estava inserida. Vemos como toda experiência religiosa traz elementos híbridos, e especialmente hoje, em nossas sociedades multiculturais, isto se torna mais evidente. Nenhuma religião pode ser experimentada de forma pura, fora das culturas concretas e das situações sociais, existenciais e religiosas em que se inserem.

\section{Nível. Aprofundar em aspectos concretos da experiência mística}

Para uma teologia das religiões que favoreça o diálogo inter-religioso, é preciso conhecer cada vez mais profundamente as outras religiões, evitando as afirmações abstratas e apriorísticas. ${ }^{12}$ Faz-se necessário, igualmente, observar elementos da própria religião e das demais que tragam potencialidade de diálogo. A oração é, sem dúvida, o elemento das religiões de maior virtualidade dialogal. Natale Terrin chama a oração de "alma do mundo religioso e elemento fundamental de encontro de todas as religiões". ${ }^{13}$ Os Encontros de Assis acontecidos em 1986 e 2002, bem como o que está às portas de acontecer (outubro de 2011), demonstram a força da oração como propiciadora de unidade.

Dentro do vasto mundo da oração teresiana, destacamos aqui três elementos que, ao nosso ver, possuem potencialidade dialogal. São eles a

\footnotetext{
${ }^{12}$ Cf. Mário de F. MIRANDA, O cristianismo em face das religiões. Loyola, São Paulo, 1998, p. 15.

${ }_{13}$ Aldo Natale TERRIN, Introdução ao estudo comparado das religiões. Paulinas, São Paulo, 2003, p. 120.
} 
prática da oração de recolhimento, a relação entre oração e ética e um ponto doutrinal da mística teresiana: a presença de Deus em todas as coisas e de todas as coisas em Deus.

\section{a) A oração de recolhimento}

A oração de recolhimento caracteriza a forma teresiana de oração e será explicitada em todos os livros doutrinais de Santa Teresa: Livro da Vida, Caminho de Perfeição e Castelo Interior ou Moradas. Não se pode dizer que Teresa tenha iniciado esta forma de oração, pois esta atravessa a história cristã com características diversas. Mas podemos dizer que a Doutora da Igreja a explicita de forma original e a descreve de maneira inigualável em seus elementos, como a entrada dentro de si mesmo (abandonando uma exterioridade dilacerante) e o desenvolvimento de um encontro profundo com o Mestre e Amigo que se comunica à pessoa. Neste encontro, buscam-se os sentimentos profundos do outro e o desenvolvimento de uma comunicação rica no olhar, ouvir e, principalmente, amar.

Já se escreveu que é possível traçar um diálogo dialético entre a oração de recolhimento, a mística sufista e o zen budismo. Aqui nos interessam os movimentos de meditação que se estendem entre nós, de modo especial na linha da yoga, com a qual o recolhimento teresiano possui afinidades que chegam a impressionar. Igualmente é aberta ao diálogo dialético com o caminho hinduista devocional da união com Deus por amor (bakthi). ${ }^{14}$

Neste breve espaço desta comunicação, limito-me a apresentar algumas indicações de Teresa, tirados do Caminho de Perfeição. Alguns capítulos deste livro que já foram chamados por Tomás Álvarez de yoga cristã ${ }^{15}$ Vamos a algumas citações, evidentemente apenas para ilustrar. A primeira citação diz respeito à oração como entrada dentro de si e como encontro com o Mestre:

"Chama-se oração de recolhimento, porque nela recolhe a alma todas as suas faculdades e entra dentro de si mesma com seu Deus... É que ali,

\footnotetext{
${ }^{14}$ Cf. Santiago GUERRA, El diálogo interreligiosos: el Carmelo teresiano-sanjuanista entre Oriente e Ocidente. In: ROS GARCIA, Salvador (coord.). La recepción de los místicos Teresa de Jesús y Juan de la Cruz, Universidad Pontificia de Salamanca/Centro Internacional de Ávila, Salamanca, 1997, p. 697-708 e Jesús CASTELLANO CERVERA, El doctorado de Santa Teresa y su nueva presencia. In: ibidem, pp. 205-228.

${ }^{15}$ Tomás ALVAREZ. Paso a paso: leyendo com Teresa su Camino de Perfección. Monte Carmelo, Burgos, 1996.
} 
recolhida em si mesma, pode ela meditar na paixão, representar à mente o Filho de Deus..." (Caminho 28, 4)

As próximas dizem respeito à necessidade da prática para um maior desenvolvimento da oração como relação com Jesus:

"No recolhimento há vários graus, há mais e menos." (Caminho 28,7)

"No começo, dá trabalho porque o corpo reclama seus direitos... se, porém, nos acostumarmos, esforçando-nos durante alguns dias, o proveito logo se manifesta. Quando começamos a oração, os sentidos se recolhem espontaneamente, como abelhas voando à colmeia, para lavrar o mel." (Caminho 28, 7)

"Isto sem diligência da nossa parte. Em recompensa dos esforços de tanto tempo, quer o Senhor que a alma tenha o domínio da própria vontade." (Caminho 28, 7)

"Os sentidos the obedecem e se recolhem interiormente ao menor aceno de que se quer recolher. Embora tornem a sair (...) não fazem o mal que antes faziam. Se de novo a vontade os chama, acodem com mais presteza, até que finalmente, ao cabo de muitas entradas repetidas, apraz ao Senhor pô-los todos em contemplação perfeita." (Caminho 28,7)

“As almas que viajam por mar, navegam com vento em popa. É de suma interesse não caminhar vagarosamente." (Caminho 28, 8)

"Depois de nos esforçarmos durante algum tempo por estar em companhia deste Senhor, ele nos entenderá até por acenos." (Caminho 29, 6)

O interior humano é templo do amor de Deus, comparado ao fogo, e a entrada dentro de si deixa a pessoa mais próxima deste fogo de amor. É o que nos diz a seguinte citação:

"Nelas (nas almas recolhidas) se acende mais prontamente a labareda do amor divino. Estando mais perto do fogo, com alguns sopros do intelecto, ao saltar uma centelhazinha que as toque, logo é total o incêndio. Estão muito bem dispostas para serem abrasadas. Não há embaraços no exterior e estão a sós com Deus." (Caminho 28, 8)

E finalmente a afirmação de que a prática não garante o encontro, o que sim garante é o próprio dom do Espírito, pelo qual nos abrimos ao amor: 
"Por desbaratada que ande a vossa imaginação, forçosamente haveis de achar entre tal Pai e tal Filho o Espírito Santo. Que ele enamore vossa vontade, e se tão grande interesse não bastar para fascinar-vos, ele, que é o Amor infinito, vos prenda com os poderosos vínculos do seu amor.” (C 26, 7).

Enfim, é possível encontrar intuições básicas e práticas oracionais e meditativas que unam ocidente e oriente, através de Teresa. Diálogo dialético, em que riquezas recíprocas possam ser compartilhadas e diferenças respeitadas.

\section{b) A relação entre mística e ética}

Trazemos aqui um estudo ilustrativo de um representante da religião hindu. Seu testemunho revela uma experiência mística intercomunicável com a mística cristã, quer dizer, experiência que não pode ser comparada ou igualada acriticamente à cristã em seus conteúdos, mas que, dentro do sistema hindu, expressa elementos reconhecíveis no sistema cristão. ${ }^{16}$ Aqui, em nosso texto, privilegiamos a relação intrínseca entre a experiência interior e a exigência de um agir ético.

Trata-se da experiência de Paramahansa Yogananda, conhecido iogue da Kriya Yoga e devoto (bhakti) hindu. Em seu livro, Autobiografia de um iogue ${ }^{17}$, são descritas fortes experiências místicas com manifestações físicas e mentais bem semelhantes à fenomenologia teresiana: corpo como imobilizado, intensa lucidez interior, conhecimento e percepção de si mesmo em união com tudo. União com tudo a partir do próprio centro - coração. "Esplendor radiante parte do núcleo de si para cada parte da estrutura universal"18. Há nova consciência de si em relação com tudo e nova consciência do todo relacionado consigo próprio. Descrição de luz, fogo, experiência de infinito, sons interiores. Decepção e vazio ao término da experiência, sentimento de estreiteza do espírito e prisão no microcosmo.

Yogananda relata que, após experiências intensas de Samadhi, entrou no que ele chama de "estado de extasiada união" com Deus. É neste estado que ele descreve seu belo diálogo com o seu mestre Sri Yukteswar ${ }^{19}$. Este o leva à consciência de que o progresso espiritual "não é medido pela exibição de poderes externos", mas pela "profundeza da bem-aventurança alcançada em

\footnotetext{
16 Tratamos aqui de "equivalentes homeomórficos", expressão de R. Panikkar. Cf. Martín VELASCO, El fenómeno místico: estudio comparado. Trotta, Madrid, 1999, p. 48.

${ }^{17}$ Paramahansa YOGANANDA, Autobiografia de um iogue. Sextante, Rio de Janeiro, 2006.

${ }^{18}$ Ibidem, p. 160.

${ }^{19}$ Ibidem, p. 164-165.
} 
meditação". Ou seja, há (como em Teresa), uma prioridade da transformação pessoal sobre os fenômenos maravilhosos. Deus é "alegria sempre nova", “inesgotável”, o "sedutor para quem não há rival”. É “insondável”, mas também é "próximo e querido". Sua existência é evidenciada pela "alegria" e pela "orientação", que leva a crescer no desapego das coisas e do desejo infindável das coisas. Leva igualmente a adotar o procedimento correto.

Portanto, a mística descrita por Yogananda conduz a uma transformação pessoal, espiritual e de orientação em direção ao que seja correto no cotidiano, no pequeno, em cada coisa. Esta é a tarefa que a mística deve empreender. Bem o mostra o conselho de Sri Yukteswar: "você não deve se embriagar demais com o êxtase. Ainda tem muito que fazer no mundo. Venha, vamos varrer a varanda; depois caminharemos ao longo do Ganges." ${ }^{20}$ E Yogananda continua: "Fui buscar a vassoura; o Mestre, eu sabia, estava me ensinando o segredo da vida equilibrada. A alma deve alongar-se sobre os abismos cosmogônicos, enquanto o corpo executa seus deveres diários". ${ }^{21}$ Portanto, a experiência mística é transformadora e integradora das dimensões da vida, e não uma evasão do comum viver.

A orientação em direção ao perdão e à não-violência - $a$-himsa, está relacionada à mesma experiência mística. Yogananda descreve $a$-himsa a partir de Gandhi (sabemos que aqui Gandhi recebe forte inspiração dos Evangelhos):

"Deve-se perdoar, qualquer que seja o insulto. Foi dito que a continuação da espécie se deve à capacidade que o homem tem de perdoar. Perdão é santidade. Graças ao perdão, o universo é mantido íntegro. O perdão é o poder dos poderosos. O perdão é sacrifício. O perdão é quietude da mente. O perdão e a gentileza são as qualidades de quem é dono do próprio ser. Eles representam a virtude eterna" 22

Poderíamos, neste momento, estabelecer uma relação desta experiência do yogue Yogananda com a experiência teresiana, lembrando a insistência de Teresa entre a mística e a ética, o amor concreto, o trabalho apostólico. E o fazemos através de uma pequena seleção do capítulo quarto das sétimas Moradas, que pode ser considerado um verdadeiro tratado sobre a mística como transformação interior que potencializa o agir ético:

\footnotetext{
${ }^{20}$ Ibidem, p. 161.

${ }^{21}$ Ibidem, p. 161.

${ }^{22}$ Ibidem, p. 481.
} 
"para que pensais que são aquelas inspirações a que me referi... e os recados que a alma envia do centro interior...? Será para se deitem e durmam? Não, não, não!" (7Moradas 4,10)

"para isto é oração... para isto serve este matrimônio espiritual: para fazer nascer sempre obras, obras." (7Moradas 4, 6).

No mesmo contexto pode ser recordada sua famosa expressão: "Marta e Maria hão de andar sempre juntas a fim de hospedar o Senhor" (7 Moradas 4,12).

A existência de uma relação intrínseca entre a mística e a ética está presente em várias religiões e é elemento de encontro entre pessoas a elas pertencentes. ${ }^{23}$ As grandes religiões não incentivam a mística apenas como experiência de força pessoal. Os exemplos poderiam ser multiplicados. ${ }^{24}$

\section{c) Um ponto doutrinal: a presença de Deus em todas as coisas e de todas as coisas em Deus.}

A experiência da presença de Deus em todas as coisas e de todas as coisas em Deus é uma forte experiência teresiana de união e integração de tudo, fundada em Deus-amor-Trindade que se autocomunica. Teresa de Jesus vai descrever que muitas vezes, em sua vida, estando em oração diante de Cristo, vinha-lhe o sentimento da presença de Deus, de uma maneira tão forte que ela não podia duvidar que ele estava "dentro" dela, como companhia, inspiração e força. Igualmente, percebe a presença de Deus "em todas as coisas" 25 . Mais de uma vez, Teresa descreverá esta presença em termos da teologia da época, que afirmava que "Deus está em todas as coisas por presença, por potência e por essência" ${ }^{26}$. Ou seja, uma presença imediata, energética e íntima. Deus está presente em cada criatura, de forma interior. Esta relação concede existência, consistência e dinamismo a tudo.

\footnotetext{
${ }^{23}$ Cf. Martín VELASCO, El fenómeno místico, p. 457-466.

${ }^{24}$ A título de ilustração, trazemos a convicção do sacerdote zen Daizen Victoria (sacerdote de tradição soto-zen) de que o zen só é "útil" se gera um envolvimento vital com o bem. O envolvimento de mosteiros zen com o fascismo estatal nas guerras da primeira metade do século XX levou a uma séria reflexão sobre a relação entre mística e ética no zen budismo. Cf. Josef SUDBRACK, Mística: a busca do sentido e a experiência do absoluto. Loyola, São Paulo, 2007, pp. 33-39.

${ }^{25}$ Livro da Vida 18, 15 e também Caminho de Perfeição 28, 11.

${ }^{26} 5$ Moradas 1,10 e Relações 54.
} 
Ao mesmo tempo, ela percebia que estava "dentro" de Deus ("toda engolfada nele"27). Este sentimento, muito vivo nela, apresentará posteriormente contornos trinitários e trará fortes compromissos éticos.

Nesta dupla experiência, rompe-se a relação com Deus como objeto e se inaugura uma nova percepção pessoal como relação com Deus-amor-Trindade e, nela, com tudo e com todos. Ao mesmo tempo, Deus é hospitalidade, Teresa está dentro dele e, pelo amor, nele permanece (1Jo 4,16). Trata-se de uma percepção de Deus em tudo e do mundo em Deus. Forte elemento doutrinal ainda não totalmente refletido teologicamente e relacionado com experiências e intuições de outras religiões, a começar da mística judaica, a cabala. ${ }^{28}$ Igualmente, há aqui pontos de diálogo com a mística oriental.

Esta experiência, presente em Teresa de Jesus e em outros místicos cristãos, em todos os tempos, pode constituir também uma contribuição para pensar a Deus em perspectiva evolucionista e ecológica. ${ }^{29}$ Reflexão que traz forte responsabilidade ética e que se torna realidade transformante quando se faz experiência, pela mística.

\section{Nível. Antropológico: valorizar a vida}

Finalmente, o último nível, antropológico. Não poderíamos finalizar esta reflexão sem dizer que a mística se atem ao essencial das religiões: ao mistério de Deus e à pessoa humana que busca este Deus desde o amanhecer, anelando a vida nova que esta relação traz. Não se atem aos aspectos predominantemente rituais, doutrinais ou organizativos das religiões, embora estes aspectos não deixem de estar presentes. Mas a ênfase está na pessoa buscadora de Deus, no Deus que quer se comunicar aos seres humanos e à vida que nasce desta história de amor. Por isso ela une pessoas e destrava preconceitos religiosos. A vida de Teresa foi a sua história de oração, ou seja, de relação com o Deus sem medidas que a transforma e lança a uma nova existência, mais livre e corajosa, mais solidária, compreensiva, relacional.

\footnotetext{
${ }^{27}$ Livro da Vida 10, 1.

${ }^{28}$ Cf., para esta reflexão em perspectiva trinitária, J. MOLTMANN, Ciência e Sabedoria. Um diálogo entre ciência natural e teologia. Loyola, São Paulo, 2007 e id., O Espírito da vida. Uma pneumatologia integral. Vozes, Petrópolis, 2010, pp. 201-203.

${ }^{29}$ Cf. A. GARCIA RUBIO. A visão científica evolucionista interpela a fé em Deus criador. Atualidade Teológica 37 (2011) 47-65.
} 
Sua mística levou à sabedoria da humildade e do amor, aprendida vitalmente no evangelho vivo que lhe foi concedido, por graça divina, experimentar e, em momentos seguintes, discernir e comunicar, não apenas ao cristianismo, mas a todos os que queiram ouvir.

Finalizamos esta reflexão dizendo que Teresa de Jesus, mesmo não tratando diretamente sobre o tema do diálogo inter-religioso, tem uma palavra a nos dar sobre este assunto, através de sua experiência mística testemunhada em seus livros. O diálogo pode ser construído em vários níveis:

- em atitudes pautadas pela humildade, pelo amor concreto e solidário e pela determinação ao diálogo aberto;

- na valorização de nossas complexidades multiculturais, pelas quais experiências religiosas diversas podem ser enriquecidas no interior de sua própria identidade;

- no aprofundamento sincero em elementos da própria religião e da dos demais, elementos estes que possuam virtualidades para o diálogo (oração, ética, pontos doutrinais concretos);

- na valorização daquilo que, ao final, é o mais importante nas religiões:

a vida do ser humano e de suas comunidades concretas.

Em tudo isto pode nos iluminar a mística de Teresa de Jesus.

\section{Referências Bibliográficas}

ALVAREZ, Tomás, Santa Teresa de Jesús. Madre de los espirituales. Monte Carmelo, Burgos, 2004.

,Paso a paso. Leyendo con Teresa su Camino de Perfección. Monte Carmelo, Burgos, 1996.

CASTELLANO CERVERA, Jesús, El doctorado de Santa Teresa y su nueva presencia. In: ROS GARCIA, Salvador (coord.). La recepción de los místicos Teresa de Jesús y Juan de la Cruz, Universidad Pontificia de Salamanca/Centro Internacional de Ávila, Salamanca, 1997, pp. 205-228. GARCIA RUBIO, A., A visão científica evolucionista interpela a fé em Deus criador. Atualidade Teológica 37 (2011) 47-65 
GUERRA, Santiago. El diálogo interreligioso: el Carmelo teresianosanjuanista entre Oriente e Ocidente. In: ROS GARCIA, Salvador (coord.). La recepción de los místicos Teresa de Jesús y Juan de la Cruz, Universidad Pontificia de Salamanca/Centro Internacional de Ávila, Salamanca, 1997, pp. 697-708

LÓPEZ BARALT, Luce, Santa Teresa de Jesús y el Islam. Los símbolos de los siete castillos concêntricos. Teresianum 33 (1982) 629-678.

MIRANDA, Mário F. O cristianismo em face das religiões. Loyola, São Paulo, 1998.

MOLTMANN, J., Ciência e Sabedoria. Um diálogo entre ciência natural e teologia. Loyola, São Paulo, 2007.

, O Espírito da vida. Uma pneumatologia integral. Vozes, Petrópolis, 2010,

PEDRERO-SÁNCHEZ, M. Guadalupe A Península Ibérica entre o oriente e o ocidente. Cristãos, muçulmanos e judeus. Atual, São Paulo, 2002.

PEDROSA-PÁDUA, Lúcia; CAMPOS, Mônica B. (orgs.), Santa Teresa. Mística para o nosso tempo. São Paulo/ Rio de Janeiro, Reflexão/ PUC-Rio, 2011.

, Relações e afeto nas cartas de Santa Teresa. In: PEDROSAPÁDUA, Lúcia e CAMPOS, Mônica B. (orgs.). Santa Teresa. Mística para o nosso tempo. São Paulo/ Rio de Janeiro, Reflexão/ PUC-Rio, 2011, pp. 187-201.

PEREIRA, Gerson L., Luzes da espiritualidade teresiana para o diálogo ecumênico e inter-religioso atual. In: PEDROSA-PÁDUA Lúcia; CAMPOS, Mônica B. (orgs.), Santa Teresa. Mística para o nosso tempo. São Paulo/ Rio de Janeiro, Reflexão/ PUC-Rio, 2011, pp. 203-225.

SUDBRACK, Josef, Mística: a busca do sentido e a experiência do absoluto. Loyola, São Paulo, 2007.

TERESA DE JESUS, Livro da Vida. In: Obras Completas. [Frei Patricio Sciadini (coord.), texto estabelecido pelo Frei Tomás ALVAREZ], Carmelitana/Loyola, São Paulo, 1995, pp. 19-291.

, Caminho de Perfeição. In: Obras Completas. [Frei Patricio Sciadini (coord.), texto estabelecido pelo Frei Tomás ALVAREZ], Carmelitana/Loyola, São Paulo, 1995, pp. 293-429.

, Castelo Interior ou Moradas. In: Obras Completas. [Frei Patricio Sciadini (coord.), texto estabelecido pelo Frei Tomás ALVAREZ], Carmelitana/Loyola, São Paulo, 1995, pp. 432-588. 
TERRIN, Aldo Natale, Introdução ao estudo comparado das religiões. Paulinas, São Paulo, 2003, p. 120.

VAZ, Henrique C. L., Experiência mística e filosofia na tradição ocidental. Loyola, São Paulo, 2000.

VELASCO, El fenómeno místico. Estudio comparado. Trotta, Madrid, 1999. YOGANANDA, Paramahansa, Autobiografia de um iogue. Sextante, Rio de Janeiro, 2006.

\section{Lúcia Pedrosa-Pádua}

Professora de Teologia na PUC-Rio. Graduou-se em Teologia pela FAJE (Belo Horizonte-MG) e doutorou-se pela PUC-Rio. Bacharel em Ciências Econômicas (UFMG). Estudou no CITeS (Ávila-Espanha) e fez estudos de pós-doutorado na Itália (PUG-Roma). Dedica-se também ao trabalho pastoral e à formação teológica de leigos e leigas através do Ataendi - Centro de Espiritualidade Teresiana (Rio).

Artigo Recebido em 30/09/2011

Artigo Aprovado em 30/11/2011 